\title{
Using mechanisms of hydrolysis and sorption to reduce siloxanes occurrence in biogas of anaerobic sludge digesters
}

Gatidou, Georgia; Arvaniti, Olga S.; Stasinakis, Athanasios S.; Thomaidis, Nikolaos S.; Andersen, Henrik Rasmus

Published in:

Bioresource Technology

Link to article, DOI:

10.1016/j.biortech.2016.09.018

Publication date:

2016

Document Version

Peer reviewed version

Link back to DTU Orbit

Citation (APA):

Gatidou, G., Arvaniti, O. S., Stasinakis, A. S., Thomaidis, N. S., \& Andersen, H. R. (2016). Using mechanisms of hydrolysis and sorption to reduce siloxanes occurrence in biogas of anaerobic sludge digesters. Bioresource Technology, 221, 205-213. https://doi.org/10.1016/j.biortech.2016.09.018

\section{General rights}

Copyright and moral rights for the publications made accessible in the public portal are retained by the authors and/or other copyright owners and it is a condition of accessing publications that users recognise and abide by the legal requirements associated with these rights.

- Users may download and print one copy of any publication from the public portal for the purpose of private study or research.

- You may not further distribute the material or use it for any profit-making activity or commercial gain

- You may freely distribute the URL identifying the publication in the public portal 


\title{
Using mechanisms of hydrolysis and sorption to reduce siloxanes occurrence in biogas of anaerobic sludge digesters
}

\author{
Georgia Gatidou ${ }^{\mathrm{a}}$, Olga S. Arvaniti ${ }^{\mathrm{a}}$, Athanasios S. Stasinakis ${ }^{\mathrm{a}^{*}}$, Nikolaos S. Thomaidis $^{\mathrm{b}}$, \\ Henrik R. Andersen ${ }^{\mathrm{c}}$ \\ ${ }^{a}$ Department of Environment, University of the Aegean, 81100 Mytilene, Greece. *Corresponding author. Tel.: \\ +30 22510 36257; fax: +30 22510 36206. E-mail address: astas@env.aegean.gr \\ ${ }^{b}$ Department of Chemistry, National and Kapodistrian University of Athens, 15771 Athens, Greece \\ ${ }^{c}$ Department of Environmental Engineering, Technical University of Denmark, Miljøvej 115, 2800 Kgs. Lyngby, \\ Denmark
}

\section{Highlights}

- Hydrolysis and sorption constants for sludge $\left(\mathrm{K}_{\mathrm{d}}\right)$ determined for cyclic siloxanes

- Hydrolysis increased with temperature and decreased with size of cyclic siloxanes

- Sorption increased with molecule size with $\log K_{d}$ values from 1.46 to 3.84

- During single-stage anaerobic digestion, $>91 \%$ of siloxanes end up in biogas

- Cyclic siloxanes volatilization predicted to be mitigated using a pre-digester

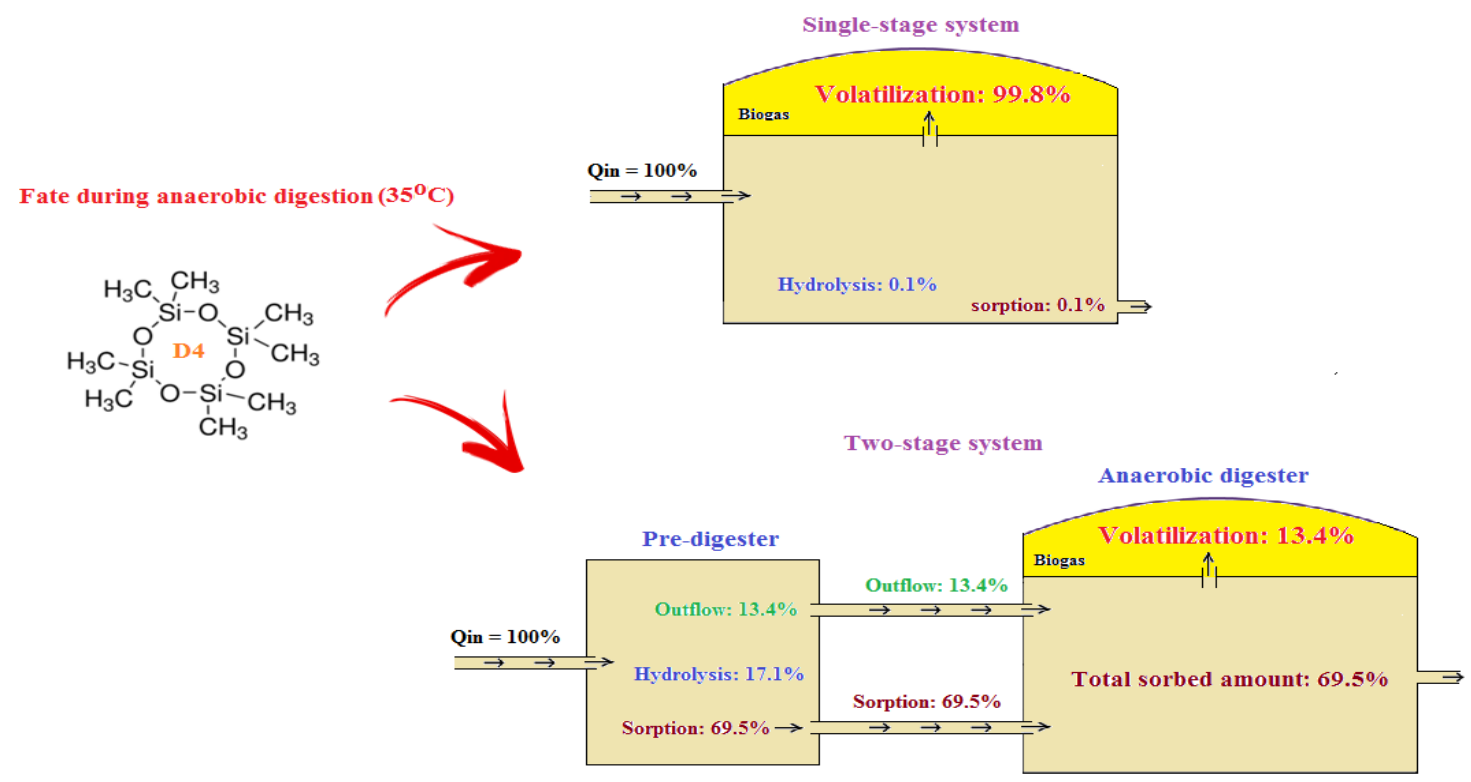

\begin{abstract}
Hydrolysis of hexamethylcyclotrisiloxane (D3), octamethylcyclotetrasiloxane (D4), decamethylcyclopentasiloxane (D5), dodecamethylcyclohexasiloxane (D6) and dodecamethylcyclohexasilane (D6_silane) and their sorption to digested sludge was studied in batch experiments. Hydrolysis was affected by the type of the compound and the applied temperature, while the relevant half-life values ranged between $0.07 \pm 0.01 \mathrm{~d}\left(\mathrm{D} 3,55^{\circ} \mathrm{C}\right)$ and $48.4 \pm 17.1 \mathrm{~d}$ (D6 silane, $4{ }^{\circ} \mathrm{C}$ ). D5 showed the greatest affinity for sorption to digested sludge $\left(\log K_{d}: 3.8 \overline{4} \pm 3.42\right)$, the lowest $\operatorname{LogK}_{d}$ value was found for D3 $(1.46 \pm 0.95)$. Prediction of investigated compounds' fate in a single-stage anaerobic digestion system indicated that volatilization seems to be the major fate in both mesophilic and thermophilic conditions. The addition of a pre-digester with $3 \mathrm{~d}$ retention time would significantly decrease the expected concentrations of all siloxanes in biogas, enhancing their removal through hydrolysis and sorption to sludge.
\end{abstract}

Keywords: micropollutants; hydrolysis; sorption; fate; sludge treatment 


\section{Introduction}

Siloxanes consist of a backbone of silicon and oxygen atoms which are alternated with organic side-chains attached to each silicon atom. These compounds can be found in linear, cyclic or tetrahedral formation with organic groups (Allen et al., 1997). Their physicochemical properties are noteworthy since they are hydrophobic and volatile at the same time depending on their molecular weight. The longer the chain length the lower the water solubility. Furthermore, these compounds are characterized by high stability, biocompatibility, surface activity and lubricating properties (Allen et al., 1997). Siloxanes can undergo hydrolysis in the environment. According to Durham $(2005,2006)$ this process is relatively slow in freshwaters under environmentally realistic conditions. Half-lives of octamethylcyclotetrasiloxane (D4) and decamethylcyclopentasiloxane (D5) have been estimated to be equal to $16.7 \mathrm{~d}$ and $315 \mathrm{~d}$ in freshwater at $\mathrm{pH} 7$ and $12{ }^{\circ} \mathrm{C}$, while the rate of hydrolysis was dependent on the $\mathrm{pH}$ and temperature. Among different siloxanes, D4 is toxic to sensitive aquatic organisms presenting long-term NOEC lower than $10 \mu \mathrm{g} \mathrm{L}^{-1}$. D5 does not exhibit adverse effects on fish and water flea at concentrations as high as $17 \mu \mathrm{g} \mathrm{L}^{-1}$ (Wang et al., 2013a) but shows considerable persistence and bioaccumulation (Sparham et al., 2008). Cyclic siloxanes have been also incriminated as potential endocrine disruptors, while they have been implicated in connective tissue disorders, adverse immunologic responses, and liver and lung damage in animal studies (Bletsou et al., 2013).

Due to their rather unusual properties, siloxanes are widely used in many applications such as antifoaming agents, coatings, shampoos, cosmetics (de Arespacochaga et al., 2015) and as a result they end up in sewage treatment plants (STPs). Occurrence of siloxanes at ppb and ppm levels in wastewater and sludge, respectively, has been reported worldwide (Wang et al., 2013b; Bletsou et al., 2013; Van Egmond et al., 2013; Liu et al., 2014) and their fate during activated sludge process has been described (Tan et al., 2017; Xu et al., 2013; Wang et al., 2015a; Wang et al., 2015b). Among the different processes that determine the removal of compounds in STPs, volatilization in the aeration tank and adsorption to sludge are the most important pathways for the elimination of siloxanes (Wang et al., 2015a).

Certain semi-volatile siloxanes have also been detected in biogas produced by anaerobically digested sludge in concentrations high enough to damage the gas motors used to convert biogas to electricity (Dewil et al., 2006; Rasi et al., 2010; Raich-Montiu et al., 2014). Despite the frequent detection of siloxanes in sludge and produced biogas, so far, their fate during sludge anaerobic digestion has not been investigated. Additionally, no information is available for the hydrolysis of these compounds at different temperatures used during anaerobic digestion $\left(35,55^{\circ} \mathrm{C}\right)$, as well as for their sorption potential in anaerobically digested sludge.

Based on the above, the main objectives of the present study were to investigate hydrolysis of selected cyclic siloxanes (hexamethylcyclotrisiloxane, D3; D4; D5; dodecamethylcyclohexasiloxane, D6; dodecamethylcyclohexasilane, D6_silane) (Table 1) under different temperatures including those typically used in mesophilic and thermophilic digestion $\left(4{ }^{\circ} \mathrm{C}, 20{ }^{\circ} \mathrm{C}, 35{ }^{\circ} \mathrm{C}\right.$ and $\left.55{ }^{\circ} \mathrm{C}\right)$, and to determine sorption distribution coefficient $\left(\mathrm{K}_{\mathrm{d}}\right)$ of these compounds in anaerobically digested sludge. Determination of investigated compounds in dissolved and solid phase was accomplished by applying a modified and fully validated previously developed (Bletsou et al., 2013) liquid-liquid extraction - gas chromatography - mass spectrometry method (LLE - GC-MS). A model was developed to predict the fate of investigated compounds during single-stage mesophilic and thermophilic anaerobic sludge digestion and to investigate the contribution of hydrolysis, sorption and volatilization to their elimination. Finally, a two-stage system was proposed to reduce the concentrations of investigated siloxanes in biogas. 


\section{Materials and Methods}

\subsection{Analytical standards and reagents}

High purity analytical standards of D3, D4, D5, D6, D6_silane and tetrakis (trimethylsiloxy)-silane (M4Q) (all $>95 \%$ purity) were purchased from Sigma-Aldich (Seelze, Germany). M4Q was used as surrogate standard for the analysis. All organic solvents including ethyl acetate, methanol, pentane, dichloromethane and isooctane were supplied by Merck (Frankfurt, Germany) and were of high purity (>95\%). $\mathrm{KH}_{2} \mathrm{PO}_{4}, \mathrm{Na}_{2} \mathrm{HPO}_{4}, \mathrm{CaCl}_{2}$ and $\mathrm{MgSO}_{4} \times 7 \mathrm{H}_{2} \mathrm{O}$ were purchased by Fluka (Buchs, Switzerland). Distilled water was provided by a MilliQ system (Milli-Q Gradient A10, Molsheim, France).

Standard stock solutions of individual compounds were prepared both in pentane and methanol at $1000 \mathrm{mg} \mathrm{L}^{-1}$ and stored in the dark at $-18{ }^{\circ} \mathrm{C}$. Mixtures of investigated analytes were prepared both in pentane and methanol at concentrations of 10 and $100 \mathrm{mg} \mathrm{L}^{-1}$. These mixtures were used to regularly prepare working standard solutions for calibration and spiking experiments.

\subsection{Hydrolysis experiments}

Hydrolysis experiments were conducted to investigate the role of this mechanism on the examined siloxanes. Phosphate buffer solution was prepared in Milli-Q water according to OECD protocol 111 in order to adjust $\mathrm{pH}$ at $7.0 \pm 0.1$ (OECD, 2004). The buffer solution was also enriched with small amounts of $\mathrm{CaCl}_{2}$ and $\mathrm{MgSO}_{4} \times 7 \mathrm{H}_{2} \mathrm{O}, 0.03 \mathrm{~g} \mathrm{~L}^{-1}$ and $0.02 \mathrm{~g} \mathrm{~L}^{-1}$, respectively. A known volume of buffer solution $(43 \mathrm{~mL})$ was placed in amber glass vials and small amounts of investigated compounds $(43 \mu \mathrm{L}$ in methanol) were added in each flask to give a final concentration of $100 \mu \mathrm{g} \mathrm{L}^{-1}$ for each siloxane, except D3 for which the final concentration was chosen to be $300 \mu \mathrm{g} \mathrm{L} \mathrm{L}^{-1}$ due to its higher quantification limit. Spiking was performed under the water surface and headspace was avoided in the vials to avoid volatilization. Experiments were made at four different temperatures $\left(4.0 \pm 1.0^{\circ} \mathrm{C}, 20.0 \pm 1.0\right.$ ${ }^{\circ} \mathrm{C}, 35.0 \pm 1.0{ }^{\circ} \mathrm{C}$ and $55.0 \pm 1.0{ }^{\circ} \mathrm{C}$ ). Flasks were wrapped in aluminium foil to prevent photodegradation. Samples were taken at selected time intervals $(3,6,15$ and $24 \mathrm{~h}$ for D3 and $3,7,12,16,20$ and $24 \mathrm{~d}$ for all the other compounds). Control runs were also performed at the same experimental conditions and samples were taken at t equal to 0 and $3 \mathrm{~h}$ to estimate the impact of spiking procedure and sorption onto flask on siloxanes removal. All experiments were conducted in triplicates.

\subsection{Sorption experiments}

Sorption experiments were performed using frieze-dried mesophilic anaerobically digested sludge taken from the Athens STP (Greece) which was prepared according to previous study (Arvaniti et al., 2014). Briefly, the preparation of the sludge was as follows: washing three times using tap water, centrifugation to remove water soluble constituents and freezing at 18 ${ }^{\circ} \mathrm{C}$ for $24 \mathrm{~h}$. Thereafter, the sludge was gently freeze dried to preserve its structure, sterilized by heating at $103{ }^{\circ} \mathrm{C}$ for minimum $3 \mathrm{~h}$ and stored at $4{ }^{\circ} \mathrm{C}$. The characteristics of digested sludge are presented in Table $\mathrm{S} 1$.

To determine $\mathrm{K}_{\mathrm{d}}$ values of the investigated compounds, batch experiments were conducted for a range of initial concentrations of each compound $\left(50,75,100,125,150\right.$ and $\left.200 \mu \mathrm{g} \mathrm{L}^{-1}\right)$. $1 \mathrm{~g} \mathrm{~L}^{-1}$ sludge and phosphate buffer solution $(43 \mathrm{~mL})$ were added in each flask, in order to avoid headspace. Batch experiments were conducted at six different concentrations $(150,225$, $300,375,450$ and $\left.600 \mu \mathrm{g} \mathrm{L}{ }^{-1}\right)$. A stir bar was added in every glass flask, in order to achieve homogeneous mixing of the samples. Flasks were covered with aluminium foil to prevent photodegradation, agitated at $120 \mathrm{rpm}$ on a shaking plate and samples were taken at the end 
of the experiment $(24 \mathrm{~h})$ for the analysis of compounds in the dissolved phase. For D3 and $\mathrm{D} 4, \mathrm{~K}_{\mathrm{d}}$ values were determined by analysing both solid and dissolved phase due to their higher instability (OECD, 2006).

Control runs without sludge were performed at the same experimental conditions to estimate the impact of other processes (e.g., spiking procedure) on siloxanes removal. Furthermore, unspiked samples were analyzed to quantify background concentration of each analyte in sludge. All the experiments were performed in triplicates at $35.0 \pm 1.0^{\circ} \mathrm{C}$ and $\mathrm{pH}$ $7.0 \pm 0.1$. Further details on the experimental design are described in Table S2.

\subsection{Siloxanes analysis}

\subsubsection{Samples pretreatment}

The analytical procedure for the extraction of wastewater and sludge samples was based on previously developed method (Bletsou et al., 2013), which was applied after several modifications and full validation.

For wastewater, $10 \mathrm{~mL}$ of filtered sample was transferred into a $50 \mathrm{~mL}$ Eppendorf tube and a known amount of M4Q (300 ng prepared in methanol) was added before extraction. After 20 min of equilibration, investigated analytes were extracted for 1 min by LLE with 10 $\mathrm{mL}$ of pentane. This solvent was chosen among others which were tested (pentane, hexane, heptane, octane) since resulted in the less contribution to the total background. Samples were extracted two more times with $2.5 \mathrm{~mL}$ mixture of pentane:dichloromethane $(50: 50, \% \mathrm{v} / \mathrm{v})$ and $2.5 \mathrm{~mL}$ of mixture pentane:ethyl acetate $(50: 50, \% \mathrm{v} / \mathrm{v})$. All three supernatants were transferred into a $15 \mathrm{~mL}$ Eppendorf tube. The combined organic layers were evaporated to a final volume of $500 \mu \mathrm{L}$ under a gentle stream of nitrogen gas $\left(\mathrm{N}_{2}\right)$. Finally, the eluents were transferred into a vial containing $500 \mu \mathrm{L}$ of pentane and subjected to GC-MS analysis.

Regarding sewage sludge, $85 \mathrm{mg}$ of dewatered sludge was transferred into a $15 \mathrm{~mL}$ Eppendorf tube. Samples were spiked prior to extraction with $300 \mathrm{ng}$ of M4Q (prepared in methanol) and allowed to equilibrate for $20 \mathrm{~min}$ at $-18{ }^{\circ} \mathrm{C}$. Then, $5 \mathrm{~mL}$ of pentane and $1 \mathrm{~mL}$ of isooctane were added into tube and shaken for 22 hours at $300 \mathrm{rpm}$ in the dark. The supernatant was collected into a $15 \mathrm{~mL}$ Eppendorf tube after centrifugation at $5000 \mathrm{rpm}$ for $10 \mathrm{~min}$. Samples were extracted three more times using $5 \mathrm{~mL}$ of pentane, $2.5 \mathrm{~mL}$ of pentane:dichloromethane $(50: 50, \% \mathrm{v} / \mathrm{v})$ and $2.5 \mathrm{~mL}$ of pentane:ethyl acetate $(50: 50, \% \mathrm{v} / \mathrm{v})$. Every extraction step was lasted $1 \mathrm{~h}$ and followed by centrifugation at $5000 \mathrm{rpm}$ for $10 \mathrm{~min}$. Finally all supernatants were combined and followed the same procedure as aforementioned for the dissolved phase samples of wastewater.

\subsubsection{GC-MS Analysis}

Analysis was performed on an Agilent 7890A GC interfaced with an Agilent 5975C MS slightly modifying the method of Bletsou et al. (2013). Separation was achieved by a DB5MS capillary column $(60 \mathrm{~m})$ with a film thickness of $0.25 \mu \mathrm{m}$ and internal diameter of $0.32 \mathrm{~mm}$ (Agilent Technologies, USA). Two $\mu \mathrm{L}$ of extract were injected using a 768313 Agilent autosampler (Agilent Technologies, USA) in a splitless mode at $200{ }^{\circ} \mathrm{C}$ and helium was used as a carrier gas at a flow rate of $1.0 \mathrm{~mL} \mathrm{~min}{ }^{-1}$. The oven temperature was programmed from $40{ }^{\circ} \mathrm{C}$ (kept for $1 \mathrm{~min}$ ); it was then increased to $220^{\circ} \mathrm{C}$ at a rate of $20^{\circ} \mathrm{C} \mathrm{min}{ }^{-1}$ and from 220 to $280{ }^{\circ} \mathrm{C}$ at a rate of $25{ }^{\circ} \mathrm{C} \mathrm{min}{ }^{-1}$, with a post-run time of $5 \mathrm{~min}$ at $300{ }^{\circ} \mathrm{C}$. The MS was operated in an electron-impact ionization mode (EI) at $70 \mathrm{eV}$, and the data were acquired by selected ion monitoring (SIM). To evaluate the best mass spectral data for each siloxane, injection of every individual compound was performed in full scan (mass range from 50-500) and the most abundant ions were selected from its spectrum. The chosen ions for SIM mode were 207, 191, 96 for D3, 281, 265, 349, 133 for D4, 355, 267 for D5, 348, 201, 215 for D6, 
281, 147, 369 for D6-silane and 341, 429, 325 for M4Q. The selected ions are in agreement with those reported in the open literature (Bletsou et al., 2013). A typical chromatogram is presented in Figure S1.

The main difficulty of siloxanes analysis is background contamination. Based on previous report (Tran et al., 2015), a number of actions were taken in order to control and minimize sources of contamination. To minimize this effect, all glassware was placed in an oven at 100 ${ }^{\circ} \mathrm{C}$ until use. As the GC vial caps were not free of silicon, vials were capped with aluminium foil which previously was baked at $100{ }^{\circ} \mathrm{C}$ for $24 \mathrm{~h}$. Furthermore, the analysts refrained from using hand lotions and other personal care products that contained siloxanes. The procedural blank was analyzed with every 10 samples and background levels of siloxanes were taken into account during interpretation of the results. Prior to instrumental analysis, pentane (reagent blank) was injected into GC-MS, until the background levels of siloxanes became stable. In addition, standard solution and spiked sample were injected after every 10 sample injection to evaluate the drift in instrumental sensitivity. Pentane was injected after every 10 samples as a check for background contamination and carry-over.

\subsection{Validation of the analytical methods}

Validation of the analytical methods included analytical methods calibration, determination of limits of detection (LODs), assessment of precision and evaluation of trueness for both dissolved and particulate phase samples.

Calibration of the GC-MS system was performed using eight different concentrations $(n=3)$ in the range of $10-1000 \mu \mathrm{g} \mathrm{L}^{-1}$. Matrix matched calibrations were also performed using fortified samples in the range of 10-1000 ng for both types of samples. For the determination of the analytical LOD, $10 \mathrm{~mL}$ of wastewater were spiked with $7 \mathrm{ng}$ of the investigated siloxanes, whereas $85 \mathrm{mg}$ of dry sludge spiked with $10 \mathrm{ng}$. LOD was calculated as three times the standard deviation of nine independent replicate analyses. Intra-day precision data was obtained by analyzing six samples $(n=6)$ spiked at a level of $30 \mu \mathrm{g} \mathrm{L}-1$ of each compound. Inter-day precision data was obtained by analyzing six samples $(n=6)$, spiked at the same level, at three different days $(k=3)$. During these experiments sludge samples were spiked with $300 \mathrm{ng}$ of siloxanes. Recovery studies were performed at three fortification levels both in wastewater $\left(10,30\right.$ and $\left.80 \mu \mathrm{g} \mathrm{L}^{-1}\right)$ and sludge $(100,300$ and $800 \mathrm{ng})$, in order to evaluate the trueness of the method.

\subsection{Calculations}

For each siloxane, the degree of removal efficiency in hydrolysis experiments was calculated using Eq. (1):

$$
\operatorname{Removal}(\%)=\frac{C_{0}-C_{W}}{C_{0}} \times 100
$$

Where, $\mathrm{C}_{0}$ is the measured concentration of each siloxane $\left(\mu \mathrm{g} \mathrm{L}^{-1}\right)$ at $\mathrm{t}=0$ in flasks (control run) and $C_{w}$ is the analyte concentration $\left(\mu \mathrm{g} \mathrm{L}^{-1}\right)$ in the dissolved phase at different time intervals.

Moreover, the obtained data from hydrolysis batch experiments were described by the pseudo first-order kinetics, (Eq. 2):

$$
C_{t}=C_{0} e^{-k_{\text {hydrolysis }} t}
$$


Where $\mathrm{C}_{\mathrm{t}}$ and $\mathrm{C}_{0}$ are the dissolved investigated compound concentrations in batch experiment at time $\mathrm{t}$ and $\mathrm{t}=0$, respectively, $\left(\mu \mathrm{g} \mathrm{L}^{-1}\right), k_{\text {hydrolysis }}$ is the hydrolysis coefficient $\left(\mathrm{h}^{-1}\right.$ or $\left.\mathrm{d}^{-1}\right)$ and $t$ is the time at the end of experiments (hours or days).

Sludge-water distribution coefficients $\left(\mathrm{L} \mathrm{Kg}^{-1}\right)$ of investigated compounds were estimated from sorption experiments according to Eq. 3:

$$
K_{d}=\frac{C_{s}}{C_{w}}
$$

Where, $\mathrm{C}_{\mathrm{s}}$ and $\mathrm{C}_{\mathrm{w}}$ are the equilibrium concentration of each investigated compound in sludge (ng $\mathrm{Kg}^{-1}$ ) and water $\left(\mathrm{ng} \mathrm{L}^{-1}\right.$ ), respectively. As mentioned in Paragraph 2.3, $\mathrm{C}_{\mathrm{s}}$ concentration was measured for D3 and D4 to solid phase samples, whereas for the other investigated compounds $\mathrm{C}_{\mathrm{s}}$ concentration was calculated using Eq. (4),

$$
C_{s}=\frac{C_{0}-C_{w}}{S S}
$$

Where, $\mathrm{C}_{0}$ is the measured concentration of each analyte in the water phase at $\mathrm{t}=0$ in flasks with no sludge addition (ng L $\left.{ }^{-1}\right)$ and $\mathrm{SS}$ is the concentration of sludge suspension used $\left(\mathrm{Kg} \mathrm{L}^{-}\right.$ $\left.{ }^{1}\right)$.

Having in mind that investigated compounds are considered resistant to biodegradation (Graiver et al., 2003) and assuming that sorbed compounds are not subjected to hydrolysis or volatilization, Equations 5 and 6 were used to predict their fate in a single-stage mesophilic or thermophilic anaerobic digester:

$$
M_{\text {in }}=M_{\text {hydrolysis. }}+M_{\text {sorption }}+M_{\text {volatilization }}+M_{\text {out }}
$$

Where $M_{\text {in }}$ and $M_{\text {out }}$ are the masses of investigated compounds in influents and effluents, respectively ( $\left.\mu \mathrm{g} \mathrm{d}^{-1}\right), M_{\text {hydrolysis, }} M_{\text {sorption }}$ and $M_{\text {volatilization }}$ are the masses of investigated compounds that are hydrolysed, sorbed and volatilised, respectively $\left(\mu \mathrm{g} \mathrm{d}^{-1}\right)$.

$$
C_{\text {in }} Q_{\text {in }}=\left(k_{\text {hydrolysis }} C_{\text {out }} V\right)+\frac{\left(X_{T} V K_{d} C_{\text {out }}\right)}{S R T}+\left(Q_{g} H C_{\text {out }}\right)+\left(Q_{\text {out }} C_{\text {out }}\right)
$$

Where $C_{\text {in }}$ and $C_{\text {out }}$ are the concentrations of investigated compounds in influents and effluents, respectively $\left(\mu \mathrm{g} \mathrm{m}^{-3}\right), Q_{\text {in }}$ and $Q_{\text {out }}$ are the flow rates in influents and effluents, respectively $\left(\mathrm{m}^{3} \mathrm{~d}^{-1}\right), Q_{g}$ is the biogas flowrate $\left(\mathrm{m}^{3} \mathrm{~d}^{-1}\right), k_{\text {hydrolysis }}$ and $K_{d}$ are the experimentally calculated hydrolysis and sorption constants, respectively, $X_{T}$ is the concentration of suspended solids $\left(\mathrm{g}\right.$ TSS L $\left.\mathrm{L}^{-1}\right), V$ is the volume of anaerobic digester $\left(\mathrm{m}^{3}\right)$, SRT is the sludge residence time in anaerobic digester (d) and $H$ is the Henry's Law coefficient at $35^{\circ} \mathrm{C}$ or $55^{\circ} \mathrm{C}\left(\mathrm{m}^{3}\right.$ liquid $/ \mathrm{m}^{3}$ gas $)$.

It should be mentioned that siloxanes are neither classified as base or acid compounds, the biogas amount was calculated from the volatile suspended solids (VSS) reduction at a rate of $1 \mathrm{~m}^{3}$ biogas per Kg VSS removed (Tchobanoglous et al., 2002), while Henry constants were estimated for $35^{\circ} \mathrm{C}$ and $55^{\circ} \mathrm{C}$ using Equation 7:

$$
H=H_{25} \theta^{(T-25)}
$$


Where $H_{25}$ is the Henry's Law coefficient at $25{ }^{\circ} \mathrm{C}\left(\mathrm{m}^{3}\right.$ liquid $\mathrm{m}^{-3}$ gas $\left.^{-1}\right), T$ is temperature at $35{ }^{\circ} \mathrm{C}$ or $55{ }^{\circ} \mathrm{C}$ and $\theta$ is the temperature correction factor (dimensionless). Value of $\theta$ was considered equal to 1.044, based on Gossett (1987) and TOXCHEM (2012). $H_{25}$ was calculated using the Equation 8 (Kochetkov et al., 2001):

$$
H_{25}=\frac{P_{25}}{R T S_{25}}
$$

Where $P_{25}$ is the vapour pressure at $25^{\circ} \mathrm{C}(\mathrm{Pa}), \mathrm{S}_{25}$ is the water solubility at $25^{\circ} \mathrm{C}\left(\mathrm{mole} / \mathrm{m}^{3}\right)$, $\mathrm{R}$ is the gas constant $\left(\mathrm{Pa} \mathrm{m}^{3} \mathrm{~K}^{-1} \mathrm{~mole}^{-1}\right)$ and $\mathrm{T}$ is the temperature $(\mathrm{K})$.

The software GraphPad Prism 5 for Windows was used for data evaluation.

\section{Results and Discussion}

\subsection{Validation of the analytical method}

Satisfactory linearity was observed all along the tested area of concentration for all the compounds both during instrumental and matrix matched calibrations with coefficients of correlation $\left(R^{2}\right)>0.99$. The obtained LODs varied from 2.2 (D4) to 4.6 (D6) $\mathrm{ng} \mathrm{mL}^{-1}$ and from 0.1 (D4) to 1.8 (D5) $\mathrm{ng} \mathrm{mg}^{-1}$ for wastewater and sludge, respectively (Table S3). These values are higher compared to other authors (Bletsou et al., 2013). However, it should be taken into account the lower preconcentration factors in the present study (only $10 \mathrm{~mL}$ of wastewater and $85 \mathrm{mg}$ of sludge were extracted) compared to others. The precision experiments shown acceptable repeatability and reproducibility of the analytical procedures, both during the same day and between days (RSDs $<10.2 \%$ ) (Table S4). Furthermore, satisfactory recoveries were observed for most of the tested siloxanes for both type of samples, ranging from $67 \%$ (D4) to $110 \%$ (D6_silane) with RSDs $\leq 13 \%$ (Tables S5 and S6). For wastewater samples, D3 was the only compound for which low recoveries were observed (Table S5), while for sludge samples D5 shown very high recoveries (up to 158\%) but with good repeatability (RSDs $\leq 4.4 \%$ ) (Table S6). In general, the results are comparable with those reported by other authors, although much lower amounts of wastewater and sludge sample were extracted (Bletsou et al., 2013; Sanchís et al., 2013). The low recovery of D3 has also reported by other authors (Sanchís et al., 2013) and it is due to the high vapour pressure of this compound.

\subsection{Hydrolysis experiments}

According to the results all tested siloxanes undergo hydrolysis. D3 was found to be the most sensitive among the five compounds (Figure 1a). About $70 \%$ of its initial concentration disappeared after $15 \mathrm{~h}$ even at $4{ }^{\circ} \mathrm{C}$, while the elimination increased with the increase of temperature $\left(90 \%\right.$ loss at $55{ }^{\circ} \mathrm{C}$ in $\left.15 \mathrm{~h}\right)$ since the rate of hydrolysis is temperature dependent with shorter half-lives at higher temperatures (Wang et al., 2013b).

Hydrolysis of other investigated compounds was much slower and it decreased with the increase in chain length (Figure 1b). D4 loss due to hydrolysis reached 70\%, 95\%, 96\% and $97 \%$ at $4,20,35$ and $55{ }^{\circ} \mathrm{C}$, respectively, after $24 \mathrm{~d}$ of experiment. D5 reduction was evident after the $3^{\text {rd }}$ day of the experiment and at the end of the experiment varied between $46 \%$ and $84 \%$ at $4{ }^{\circ} \mathrm{C}$ and $55{ }^{\circ} \mathrm{C}$, respectively. As for $\mathrm{D} 6,48 \%$ of the compound was hydrolysed throughout the experiment at $4{ }^{\circ} \mathrm{C}$, while its removal ranged up to $71 \%$ at $55{ }^{\circ} \mathrm{C}(24 \mathrm{~d})$. Finally, D6_silane concentration loss varied from $32 \%\left(4{ }^{\circ} \mathrm{C}\right)$ to $56 \%\left(55{ }^{\circ} \mathrm{C}\right)$ during the experiment $(24 \mathrm{~d})$. Other authors have also reported lower hydrolysis rates regarding investigated compounds as their molecule increases (Environmental Agency 2009a, b, c). A 
possible explanation for this "protection" against hydrolysis could be the effect of steric hindrance of the compounds.

First order kinetic equation was fitted to concentration profiles at each of the examined temperatures. The significance of the effect of temperature on the hydrolysis rate constant was analyzed by F-test in GraphPad Prism 5 with the null hypothesis being that the rate constant for degradation is similar at all the tested temperatures, for each siloxane, which revealed a statistical clear effect with $\mathrm{P}=0.0032$ for $\mathrm{D} 6$ and $\mathrm{P}<0.0001$ for the other compounds. The degradation rate constants were also significantly different between the investigated siloxanes at the four investigated temperatures with $\mathrm{P}<0.0001$ except for $4{ }^{\circ} \mathrm{C}$ there $\mathrm{P}=0.0248$.

The hydrolysis rate constant and the half-life of each compound were calculated with $95 \%$ confidence intervals (Table 2). The lowest half-life values were observed for D3 ranging between $0.07 \mathrm{~d}( \pm 0.01)$ at $55^{\circ} \mathrm{C}$ and $0.27 \mathrm{~d}( \pm 0.07)$ at $4{ }^{\circ} \mathrm{C}$, whereas D6 silane was found to be most stable with half-lives up to $48 \mathrm{~d}( \pm 17.1)$ at $4{ }^{\circ} \mathrm{C}$.

Dow Corning (2005) reported a half-life of $1.04 \mathrm{~d}$ for $\mathrm{D} 4$ at $\mathrm{pH} 7$ at $35^{\circ} \mathrm{C}$ which is comparable with the present value of $1.6 \mathrm{~d}$. As for the other compounds, there is no hydrolysis data in the literature for similar experimental conditions. However, at $\mathrm{pH} 7$ and 25 ${ }^{\circ} \mathrm{C}$ hydrolysis half-lives of 23 minutes and 71 days have been reported for D3 (Dow Corning, 2004) and D5 (Environment Agency, 2009b), respectively.

\subsection{Sorption experiments}

The sorption of the investigated compounds to anaerobically digested sludge was studied in flasks containing different concentrations of the target compounds at $35{ }^{\circ} \mathrm{C}$. Sorption equilibrium constants were calculated for each siloxane using Equations 3 and 4 . The results clearly distributed evenly in a linear plot of measured $\mathrm{C}_{\mathrm{w}}$ against $\mathrm{C}_{\mathrm{s}}$ and therefore no isotherm fittings were attempted. $K_{d}$ values were calculated as the average of all the $K_{d}$ determined (n $=18)$. As shown in Table $3, \log \mathrm{K}_{\mathrm{d}}$ values varied from $1.46( \pm 0.95)$ for $\mathrm{D} 3$ to $3.84( \pm 3.42)$ for D5. This is the first study that report cyclic siloxanes sorption constants onto anaerobically digested sludge.

The sorption results are generally comparable with values published for other types of sludge. Bletsou et al. (2013) estimated $\log \mathrm{K}_{\mathrm{d}}$ values for D5 and D6 in primary and secondary sludge using full-scale monitoring data of a STP and reported values ranging between 1.83 (D3) and 4.42 (D5). Wang et al. (2015) determined $\log K_{d}$ values in primary and secondary sludge as high as 3.53 (D5) and 5.57 (D5), respectively. Xu et al. (2013) found slightly lower $\operatorname{logKd}$ values in aerobic activated sludge which varied from 1.94 (D4) to 2.46 (D5). The variances observed among different studies are due to the different chemical characteristics of each type of sludge used ( $\mathrm{pH}$, organic carbon, cations). In the literature it has already been mentioned by several authors that the type of sludge affect the degree of micropollutants sorption and thus the values of $K_{d}$ (Ternes et al., 2004; Hörsing et al., 2011; Arvaniti et al., 2012).

\subsection{Prediction of siloxanes fate during single-stage anaerobic sludge digestion}

The determined hydrolysis and sorption constants as well as values of the vapour pressure values taken from the literature (Table 1) were used to predict the contribution of hydrolysis, sorption and volatilization, respectively, for D3, D4, D5 and D6 during mesophilic and thermophilic anaerobic digestion. For this reason, Equation 6 was applied for single-stage anaerobic digesters operating at SRT of $17 \mathrm{~d}$ and temperatures of $35{ }^{\circ} \mathrm{C}$ and $55{ }^{\circ} \mathrm{C}$. For the operational parameters of the anaerobic digesters (volume, SRT, flowrates, VSS removal, biogas production), the anaerobic digester of Athens STP was used as model. All values of 
different parameters used in Equation 6 as well as the operational characteristics of the anaerobic digesters are reported in Table S7. Equation 6 was not applied for D6_silane due to the lack of literature data for the vapour pressure value of this compound.

The results of the model are presented in Figure 2 as well as in Tables S8 and S9 (Scenario A). The mass balance shows that the major mechanism affecting the fate of investigated compounds for both mesophilic and thermophilic conditions is volatilization. More than $91 \%$ of all siloxanes seem to be transferred to biogas under mesophilic conditions, while this mechanism is further enhanced under thermophilic conditions, reaching $99.8 \%$ for D4. Despite the high hydrolysis constants of D3, its contribution to the removal of the investigated compound in a single-stage system was not of high importance, ranging up to $8.2 \%\left(35^{\circ} \mathrm{C}\right)$. The contribution of hydrolysis for the other siloxanes did not exceed $0.2 \%$. Small fractions of D5 (3.9\%) and D6 (2.2\%) seem to be sorbed onto sludge during mesophilic digestion, while even smaller sorbed amounts are estimated for thermophilic conditions. The role of this mechanism seems to be negligible for D3 and D4.

So far, the fate of the investigated cyclic siloxanes during anaerobic digestion has not been studied and the contribution of different mechanisms has not been investigated. Several previous articles suggested that D3, D4 and D5 were among the most prevalent siloxanes in biogas produced in STPs and biogas plants. Concentrations ranging between 40 and $420 \mu \mathrm{g}$ $\mathrm{m}^{-3}$ for D3, 30 to $10120 \mu \mathrm{g} \mathrm{m}{ }^{-3}$ for D4 and 100 to $15500 \mu \mathrm{g} \mathrm{m}^{-3}$ for D5 have been reported (Rasi et al., 2010; Tansel and Surita, 2014; Raich-Montiu et al., 2014). Back-calculation of the results of this study shows that for the model anaerobic digester used and mesophilic conditions, concentrations equal to $670 \mu \mathrm{g} \mathrm{m}^{-3}, 728 \mu \mathrm{g} \mathrm{m}^{-3}$ and $700 \mu \mathrm{g} \mathrm{m}^{-3}$ are estimated for D3, D4 and D5 respectively, in biogas. These concentrations are the same order of magnitude with those reported in the literature.

To investigate the sensitivity of the mass balance based model to possible differences of the experimentally calculated constants of this study, two different scenarios $(B, C)$ were tested and the results are given in Tables S8 (mesophilic digester) and S9 (thermophilic digester). Specifically, an increase of $k_{\text {hydrolysis }}$ values by $50 \%$ (Scenario B) would increase the contribution of this mechanism on D3 removal by 3.5\% (mesophilic conditions) or $2.4 \%$ (thermophilic conditions), whereas no important effect would be noticed for the other compounds. On the other hand, an increase of $K_{d}$ values by $50 \%$ (Scenario C) would not actually affect the behaviour of D3 and D4, while it would increase by $1.9 \%$ and $1.0 \%$ the contribution of sorption on D5 and D6 removal under mesophilic conditions, respectively (Table S8). A slight increase of sorbed amounts of these two compounds is also predicted for thermophilic conditions (Table S9). The aforementioned calculations indicate that a possible underestimation by $50 \%$ of hydrolysis and sorption constants in this study would not affect significantly the results regarding the fate of the investigated siloxanes during sludge anaerobic digestion. Future monitoring studies in full-scale anaerobic digesters should be performed to confirm the results of the prediction model developed in this article.

\subsection{Use of a two-stage system for decreasing siloxanes concentration in biogas}

The occurrence of siloxanes in biogas is responsible for commonly observed damages in the gas motors (Rasi et al., 2010; Raich-Montiu et al., 2014), resulting in increased cost for renovation or treatment of the produced biogas by activated carbon sorption (Soreanu et al., 2011). On the other hand, the short hydrolysis half-lives of D3 and D4 $(<2 \mathrm{~d}$, Table 2$)$ indicate that the operation of a pre-digester tank with low hydraulic residence time (HRT) could give a significant elimination of the investigated compounds due to hydrolysis and much lower siloxanes concentrations in the biogas of the following anaerobic digester. Similar predigester reactors operated at short retention times and neutral $\mathrm{pH}$ have been used in the 
literature to improve sludge solubilisation and overall biogas production of the system. Having in mind the high sorption coefficients of longer siloxanes (Table 3), sorption could also be an important mechanism governing the fate of these compounds in this pre-digester tank.

To test this hypothesis, a two-stage system was considered consisting of a pre-digester (Tank 1, HRT: 3 d) and an anaerobic digester (Tank 2), operating at the same conditions described before (Table S7), and the fate of investigated siloxanes was predicted for mesophilic and thermophilic conditions. Equation 6 was used for both reactors with the difference that volatilization was considered negligible at the pre-digester due to its low HRT which prevent methanogens from developing. The results presented in Figure 3 reveal that more than $92 \%$ of D3 and an important part of D4 is expected to be removed via hydrolysis in the pre-digester tank under both mesophilic and thermophilic conditions. Additionally, the major part of D5 and D6 (>98\%) is seen to accumulate in sludge in Tank 1, while significant sorbed amounts are also predicted for D4 under mesophilic (69.5\%) and thermophilic conditions $(47.5 \%)$. Due to the aforementioned mechanisms occurring in the pre-digester, the amount of siloxanes that volatilize in the anaerobic digester is much smaller. As a result, just $4.0 \%$ of D3 and $13.4 \%$ of D4 can be predicted to be transferred to the biogas in the mesophilic reactor, while even lower fractions are predicted for thermophilic reactor. Much lower fractions are also predicted for D5 and D6 in biogas (Figure 3). Back-calculation of these results shows that the expected concentrations of D3, D4 and D5 in the biogas are one or two order of magnitude lower than those estimated in single-stage system, ranging between $4.0 \mu \mathrm{g} \mathrm{m}^{-3}$ (D5, mesophilic conditions) and $97.3 \mu \mathrm{g} \mathrm{m}^{-3}$ (D4, mesophilic conditions).

\section{Conclusions}

D3 was rapidly hydrolysed at all tested temperatures, while hydrolysis of other siloxanes was slower. The increase of temperature accelerated hydrolysis of investigated siloxanes. Sorption was different among the investigated compounds with logKd values ranging from 1.46 (D3) to 3.84 (D5). The fate of cyclic siloxanes during single-stage anaerobic digestion is affected mainly by volatilization and transfer to biogas. Mass balances predict that the use of a predigester in a two-stage system could increase hydrolysis of D3, D4 and sorption of D4, D5 and D6 resulting in mitigation of the significant problem of siloxanes in biogas produced from sewage sludge.

\section{Acknowledgments}

This research was co-financed by the European Union (European Social Fund - ESF) and Greek national funds through the Operational Program "Education and Lifelong Learning" of the National Strategic Reference Framework (NSRF) - Research Funding Program: THALES-WATERMICROPOL, http://www2.env.aegean.gr/WaterMicropol/).

\section{References}

Adriani, D., Wresta, A., Atmaja, T.D., Saepudin, A., 2014. A review on optimization production and upgrading biogas through $\mathrm{CO}_{2}$ removal using various techniques. Appl. Biochem. Biotechnol. 172, 1909-1928.

Allen, R.B., Kochs, P., Chandra, G., 1997. Organosilicon Materials: The Handbook of Environmental Chemistry / Anthropogenic Compounds, Volume 3, part H. SpringerVerlag, Berlin.

Arvaniti, O.S., Ventouri, E.I., Stasinakis, A.S., Thomaidis, N.S. 2012. Occurrence of different classes of perfluorinated compounds in Greek wastewater treatment plants and 
determination of their solid-water distribution coefficients. J. Hazard. Mater. 239-240, 2431.

Arvaniti, O.S., Andersen, H.R., Thomaidis, N.S., Stasinakis, A.S. 2014. Sorption of perfluorinated compounds onto different types of sewage sludge and assessment of its importance during wastewater treatment. Chemosphere 111, 405-411.

Bletsou, A.A, Asimakopoulos, A.G., Stasinakis, A.S., Thomaidis, N.S., Kannan, K., 2013. Mass Loading and Fate of Linear and Cyclic Siloxanes in a Wastewater Treatment Plant in Greece. Environ. Sci. Technol. 47, 1824-1832.

De Arespacochaga, N., Valderrama, C., Raich-Montiu, J., Crest, M., Mehta, S., Cortina, J.L., 2015. Understanding the effects of the origin, occurrence, monitoring, control, fate and removal of siloxanes on the energetic valorization of sewage biogas - A review. Renew. Sustainable Energy Rev. 52, 366-381.

Dewil, R., Appels, L., Baeyens, J., 2006. Energy use of biogas hampered by the presence of siloxanes. Energ. Convers. Manage. 47, 1711-1722.

Dow Corning, 2004. Hydrolysis of Hexamethylcyclotrisiloxane (D3). Final Report, HES Study No. 9760-102. Auburg, MI: Health and Environmental Sciences, Dow Corning Corporation.

Dow Corning, 2005. Hydrolysis of Octamethylcyclotetrasiloxane (D4). HES Study No. 10000-102. Auburg, MI: Health and Environmental Sciences, Dow Corning Corporation.

Durham, J., 2005. Hydrolysis of Octamethylcyclotetrasiloxane (D4). Silicones Environment, Health and Safety Council. Study Number 10000-102.

Durham, J., 2006. Hydrolysis of Octamethylcyclotetrasiloxane (D5) Silicones Environment, Health and Safety Council. Study Number 10040-102.

Environment Agency, 2009a. Environmental Risk Assessment Report: Dodecamethylcyclohexasiloxane Final Draft Report. Bristol: Environment Agency.

Environment Agency, 2009b. Environmental Risk Assessment Report: Decamethylcyclopentasiloxane. Final Draft Report. Bristol: Environment Agency.

Environment Agency, 2009c. Environmental Risk Assessment Report: Octamethylcyclotetrasiloxane. Final Draft Report. Bristol: Environment Agency.

Ge, H., Jensen, P.D., Batstone, D.J., 2011. Increased temperature in the thermophilic stage in temperature phased anaerobic digestion (TPAD) improves degradability of waste activated sludge. J. Hazard. Mater. 187, 355-361.

Gossett, J.M., 1987. Measurement of Henry's law constants for C1 and C2 chlorinated hydrocarbons. Environ. Sci. Technol. 21, 202-208.

Graiver, D., Farminer, K.W., Narayan, R., 2003. A review on the fate and effects of silicones in the environment. J. Polym. Environ. 11, 129-136.

Hörsing, M., Ledin, A., Grabic, R., Fic, J., Tysklind, M., Jansen, J.L.C., Andersen, H.R., 2011. Determination of sorption of seventy-five pharmaceuticals in sewage sludge. Water Res. 45, 4470-4482.

Kochetkov, A., Smith, J.S., Raghunathan, R., Valsaraj, K.T., Thibodeaux, L.J., 2001. Airwater partition constants for volatile methyl siloxanes. Environ. Tox. Chem. 20, 21842188.

Liu, N., Shi, Y., Li, W., Xu, L., Cai, Y., 2014. Concentrations and distribution of synthetic musks and siloxanes in sewage sludge of wastewater treatment plants in China. Sci. Total Environ. 476-477, 65-72.

Matsui, T., Imamura S., 2010. Removal of siloxane from digestion gas of sewage sludge. Bioresour.Technol. 101, S29-S32.

OECD Guidelines for the testing of chemicals. 2004. Test No111: Hydrolysis as a function of pH, pp. 1-15 (http:// http://www.oecd-ilibrary.org/, last access 03.02.2016). 
OECD Guidelines for the testing of chemicals. 2006. Test No106: Adsorption - Desorption Using a Batch Equilibrium Method, pp. 1-45 (http:// http://www.oecd-ilibrary.org/, last access 03.02.2016).

Palczewska-Tulińska, M., Oracz, P., 2005 Selected physicochemical properties of Hexamethylcyclotrisiloxane, Octamethylcyclotetrasiloxane, and Decamethylcyclopentasiloxane. J. Chem.Eng. Data 50, 1711-1719.

Raich-Montiu, J., Ribas-Font, C., De Arespacochaga, N., Roig-Torres, E., Broto-Puig, F., Crest, M., Bouchy, L., Cortina, J.L., 2014. Analytical methodology for sampling and analysing eight siloxanes and trimethylsilanol in biogas from different wastewater treatment plants in Europe. Anal. Chim. Acta 812, 83-91.

Rasi, S., Lehtinen, J., Rintala, J., 2010. Determination of organic silicon compounds in biogas from wastewater treatment plants, lanfills and co-digestion plants. Renew. Energy 35, 2666-2673.

Sanchís, J., Martínez, E., Ginebreda, A., Farré, M., Barceló D., 2013. Occurrence of linear and cyclic volatile methylsiloxanes in wastewater, surface water and sediments from Catalonia. Sci. Total Environ. 443, 530-538.

Soreanu, G., Beland, M., Faletta, P., Edmonson, K., Svoboda, L., Al-Jamal, M., Seto, P., 2011. Approaches concerning siloxane removal from biogas - A review. Can. Biosyst. Eng. 53, 8.1-8.18.

Sparham, C., Van Egmond, R., O'Connor, S., Hastie, C., Whelan, M., Kanda, R., Franklin, O., 2008. Determination of decamethylcyclopentasiloxane in river water and final effluent by headspace gas chromatography/mass spectrometry. J. Chromatogr. A 1212 , 124-129.

Tansel, B., Surita, S.C., 2014. Differences in volatile methyl siloxane (VMS) profiles in biogas from landfills and anaerobic digesters and energetics of VMS transformations. Waste Manage. 34, 2271-2277.

Tchobanoglous, G., Burton, F.L, Stensel, D.H., 2002. Wastewater Engineering: Treatment Disposal Reuse. $4^{\text {th }}$ ed.: Mc Graw Hill, Boston, USA.

Ternes, T.A., Herrmann, N., Bonerz, M., Knacker, T., Siegrist, H., Joss, A. 2004. A rapid method to measure the solid-water distribution coefficient $\left(\mathrm{K}_{\mathrm{d}}\right)$ for pharmaceuticals and musk fragrances in sewage sludge. Water Res. 38, 4075-4084.

Toxchem, 2012. Modeling the fate of toxics in wastewater treatment plants. Technical Guide, version 4.1, Hydromantis Environmental Software Solutions Inc., Canada.

Tran, T.M., Abualnaja K.O., Asimakopoulos A.G., Covaci A., Gevao B., Johnson-Restrepof B., Kumosani T.A., Malarvannan G., Minh T.B., Moon H.B., Nakata H., Sinha R.K., Kannan K., 2015. A survey of cyclic and linear siloxanes in indoor dust and their implications for human exposures in twelve countries. Environ Int. 78, 39-44.

Van Egmond, R., Sparham, C., Hastie, C., Gore, D., Chowdhury, N., 2013. Monitoring and modelling of siloxanes in a sewage treatment plant in the UK. Chemosphere 93, 757-765.

Wang D.G., Norwood, W., Alaee, M., Byer, J.D., Brimble S., 2013a. Review of recent advances in research on the toxicity, detection, occurrence and fate of cyclic volatile methyl siloxanes in the environment. Chemosphere 93, 711-725.

Wang, D.G., Alaee, M., Steer, H., Tait, T., Williams, Z., Brimble, S., Svoboda, L., Barresi, E., DeJong, M., Schachtschneider, J., Kaminski, E., Norwood, W., Sverko, E., 2013 b. Determination of cyclic volatile methylsiloxanes in water, sediment, soil, biota, and biosolid using large-volume injection-gas chromatography-mass spectrometry. Chemosphere 93, 741-748. 
Wang, D.G., Aggarwal, M., Tait, T., Brimble, S., Pacepavicious, S., Kinsman, L., Theocharides, M., Smith, S.A., Alaee, M., 2015a. Fate of anthropogenic cyclic volatile methylsiloxanes in a wastewater treatment plant, Water Res. 72, 209-217.

Wang, D.G., Du, J., Pei, W., Liu, Y., Guo, M., 2015b. Modeling and monitoring cyclic and linear siloxanes in a wastewater treatment plant using constant level sequencing batch reactors. Sci. Total Environ. 512-513, 472-479.

$\mathrm{Xu}, \mathrm{S}$., Kropscott, B., 2012. Method for simultaneous determination of partition coefficients for cyclic volatile methylsiloxanes and dimethylsilanediol. Anal. Chem. 84, 1948-1955.

Xu, L., Shi, Y., Cai, Y., 2013. Occurrence and fate of volatile siloxanes in a municipal Wastewater Treatment Plant of Beijing, China. Water Res. 47, 715-724. 
Table 1. Abbreviations, structures, molecular weights and physico-chemical properties of target cyclic siloxanes.

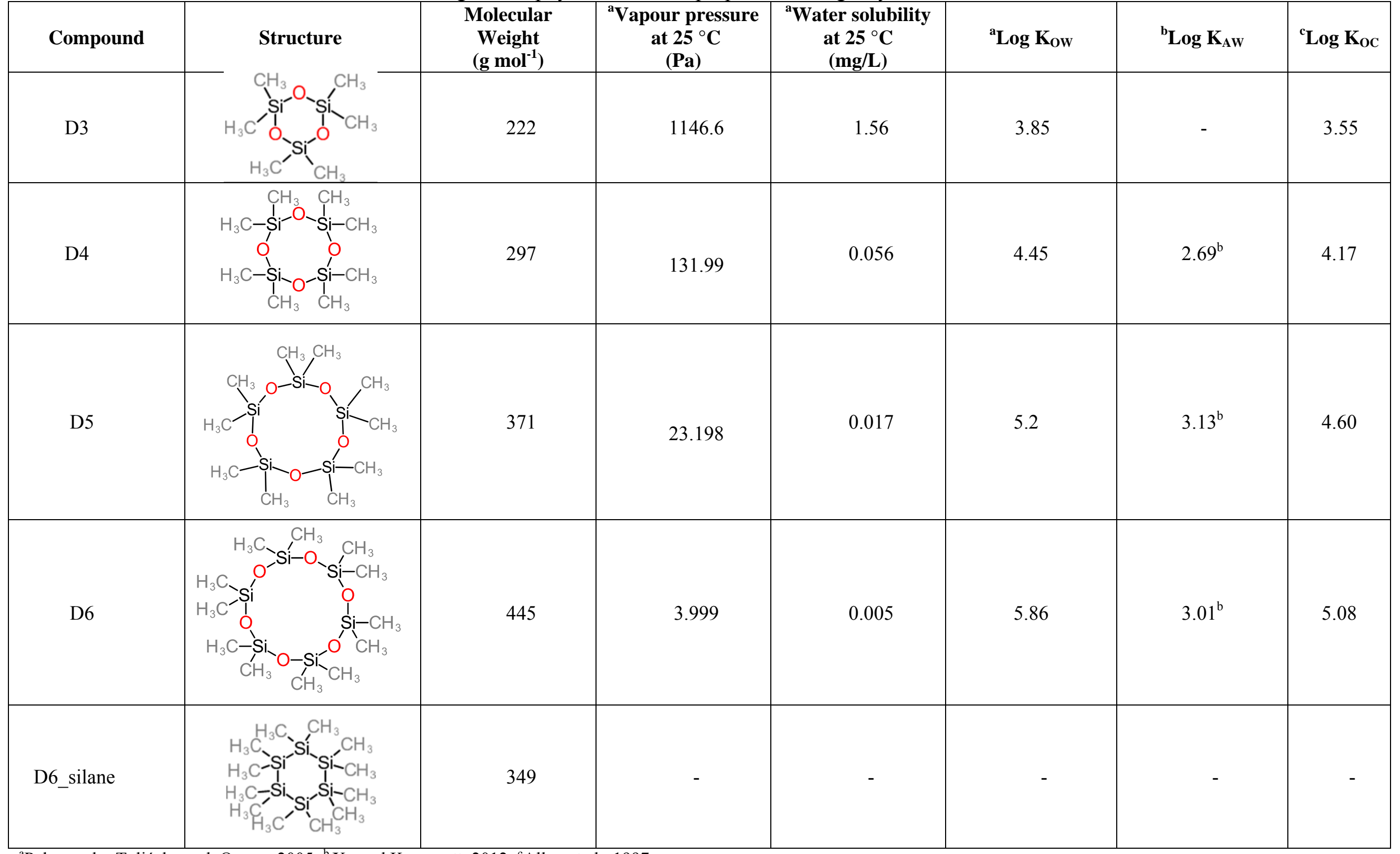

${ }^{\mathrm{a}}$ Palczewska-Tulińska and Oracz, 2005; ${ }^{\mathrm{b}} \mathrm{Xu}$ and Kropscott, 2012; ${ }^{\mathrm{c}}$ Allen et al., 1997 
Table 2. First order kinetics ( $\mathrm{k}_{\text {hydrolysis }}$ ), half-life values and $\mathrm{R}^{2}$ of target compounds, calculated during hydrolysis experiments under different experimental temperature conditions. The $95 \%$ confidence intervals of measured values are given in parenthesis.

\begin{tabular}{|c|c|c|c|c|}
\hline Compound & Temperature $\left({ }^{\circ} \mathrm{C}\right)$ & $\boldsymbol{k}_{\text {hydrolysis }}\left(\mathrm{d}^{-1}\right)$ & Half-life $(\mathrm{d})$ & $\boldsymbol{R}^{\mathbf{2}}$ \\
\hline \multirow{4}{*}{ D3 } & $4{ }^{\circ} \mathrm{C}$ & $2.5( \pm 0.90)$ & $0.27( \pm 0.07)$ & 0.85 \\
\cline { 2 - 5 } & $20{ }^{\circ} \mathrm{C}$ & $4.1( \pm 1.67)$ & $0.17( \pm 0.05)$ & 0.83 \\
\cline { 2 - 5 } & $35^{\circ} \mathrm{C}$ & $7.2( \pm 2.74)$ & $0.10( \pm 0.03)$ & 0.88 \\
\cline { 2 - 5 } & $55^{\circ} \mathrm{C}$ & $10.3( \pm 2.80)$ & $0.07( \pm 0.01)$ & 0.96 \\
\hline \multirow{4}{*}{ D4 } & $4{ }^{\circ} \mathrm{C}$ & $0.05( \pm 0.02)$ & $15.2( \pm 4.3)$ & 0.63 \\
\cline { 2 - 5 } & $20{ }^{\circ} \mathrm{C}$ & $0.17( \pm 0.05)$ & $4.1( \pm 0.9)$ & 0.88 \\
\cline { 2 - 5 } & $35{ }^{\circ} \mathrm{C}$ & $0.43( \pm 0.08)$ & $1.6( \pm 0.3)$ & 0.97 \\
\hline \multirow{4}{*}{ D5 } & $55^{\circ} \mathrm{C}$ & $1.58( \pm 0.20)$ & $0.4( \pm 0.05)$ & 0.99 \\
\cline { 2 - 5 } & $4{ }^{\circ} \mathrm{C}$ & $0.03( \pm 0.01)$ & $21.8( \pm 5.0)$ & 0.71 \\
\cline { 2 - 5 } & $20{ }^{\circ} \mathrm{C}$ & $0.08( \pm 0.02)$ & $8.2( \pm 1.6)$ & 0.87 \\
\cline { 2 - 5 } & $35^{\circ} \mathrm{C}$ & $0.10( \pm 0.03)$ & $6.7( \pm 1.4)$ & 0.87 \\
\hline \multirow{5}{*}{ D6 } & $55^{\circ} \mathrm{C}$ & $0.11( \pm 0.03)$ & $6.2( \pm 1.4)$ & 0.85 \\
\cline { 2 - 5 } & $4{ }^{\circ} \mathrm{C}$ & $0.03( \pm 0.02)$ & $24.3( \pm 9.4)$ & 0.42 \\
\cline { 2 - 5 } & $20^{\circ} \mathrm{C}$ & $0.06( \pm 0.02)$ & $11.4( \pm 3.0)$ & 0.73 \\
\cline { 2 - 5 } & $35^{\circ} \mathrm{C}$ & $0.08( \pm 0.02)$ & $9.2( \pm 2.2)$ & 0.82 \\
\hline \multirow{5}{*}{ D6_silane } & $55^{\circ} \mathrm{C}$ & $0.05( \pm 0.02)$ & $14.8( \pm 3.9)$ & 0.78 \\
\cline { 2 - 5 } & $4{ }^{\circ} \mathrm{C}$ & $0.01( \pm 0.01)$ & $48.4( \pm 17.1)$ & 0.42 \\
\cline { 2 - 5 } & $20^{\circ} \mathrm{C}$ & $0.06( \pm 0.02)$ & $12.5( \pm 3.1)$ & 0.73 \\
\cline { 2 - 5 } & $35^{\circ} \mathrm{C}$ & $0.10( \pm 0.02)$ & $7.1( \pm 1.3)$ & 0.91 \\
\hline
\end{tabular}

Table 3. Average $\log \mathrm{K}_{\mathrm{d}}$ values for siloxanes in anaerobically digested sludge $\left(35^{\circ} \mathrm{C}\right)$ and comparison with literature data. Standard deviations of measured $\log \mathrm{K}_{\mathrm{d}}$ values are given in parenthesis.

\begin{tabular}{|c|c|c|c|c|c|c|}
\hline \multirow[b]{2}{*}{$\begin{array}{c}\text { Target } \\
\text { Analytes }\end{array}$} & \multicolumn{6}{|c|}{$\operatorname{LogK}_{d}\left(L \cdot K^{-1}\right)$} \\
\hline & $\begin{array}{c}\text { Anaerobically } \\
\text { Digested } \\
\text { Sludge }^{\mathrm{a}} \\
\end{array}$ & $\begin{array}{l}\text { Primary } \\
\text { Sludge }^{b}\end{array}$ & $\begin{array}{l}\text { Secondary } \\
\text { Sludge }^{c}\end{array}$ & $\begin{array}{l}\text { Primary } \\
\text { Sludge }\end{array}$ & $\begin{array}{l}\text { Secondary } \\
\text { Sludge }^{c}\end{array}$ & $\begin{array}{l}\text { Aerobic } \\
\text { Activated } \\
\text { Sludge }^{\mathrm{d}}\end{array}$ \\
\hline D3 & $1.46 \pm 0.95$ & 1.83 & 2.15 & - & - & 2.23 \\
\hline D4 & $2.32 \pm 1.85$ & 3.05 & 3.40 & 3.30 & 3.64 & 1.94 \\
\hline D5 & $3.84 \pm 3.42$ & 3.64 & 4.42 & 3.41 & 5.50 & 2.46 \\
\hline D6 & $3.41 \pm 2.75$ & 3.49 & 3.95 & 3.53 & 5.57 & 2.17 \\
\hline D6_silane & $2.82 \pm 2.34$ & & & & & \\
\hline
\end{tabular}

${ }^{a}$ current study; ${ }^{b}$ Bletsou et al., 2013; ${ }^{c}$ Wang et al., 2015; ${ }^{\mathrm{d}} \mathrm{Xu}$ et al., 2013 
a)

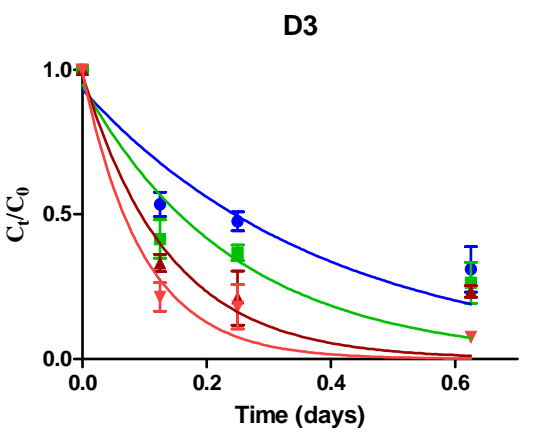

b)

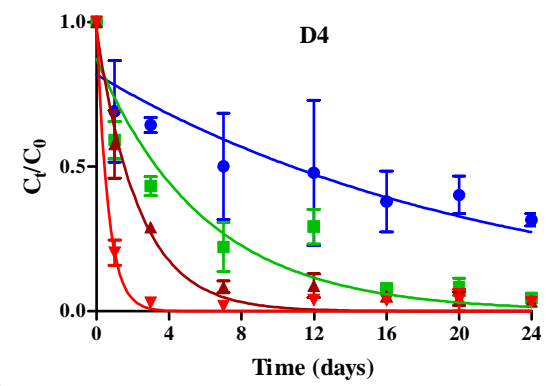

d)

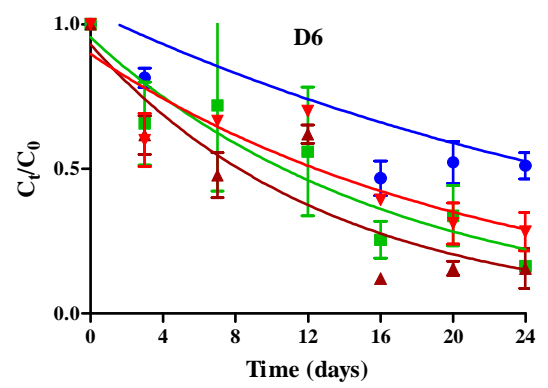

- $4{ }^{\circ} \mathrm{C}$

- $20^{\circ} \mathrm{C}$

$\triangle 35^{\circ} \mathrm{C}$

$\checkmark 55^{\circ} \mathrm{C}$

c)

e)
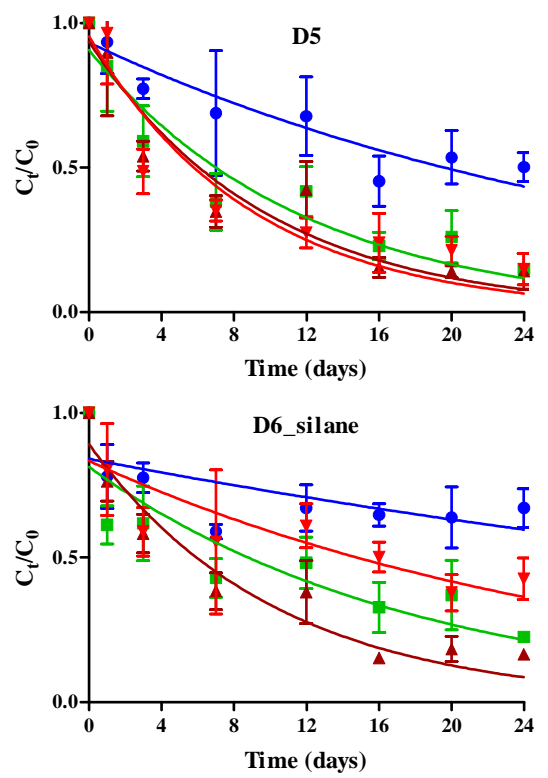

Fig. 1. Reduction of target siloxanes during hydrolysis experiments conducted at different temperatures; a) D3 (total duration of the experiment: 15 hours), b-e) D4, D5, D6, D6_silane (total duration of the experiment: 24 days). 
a) $35^{\circ} \mathrm{C}$

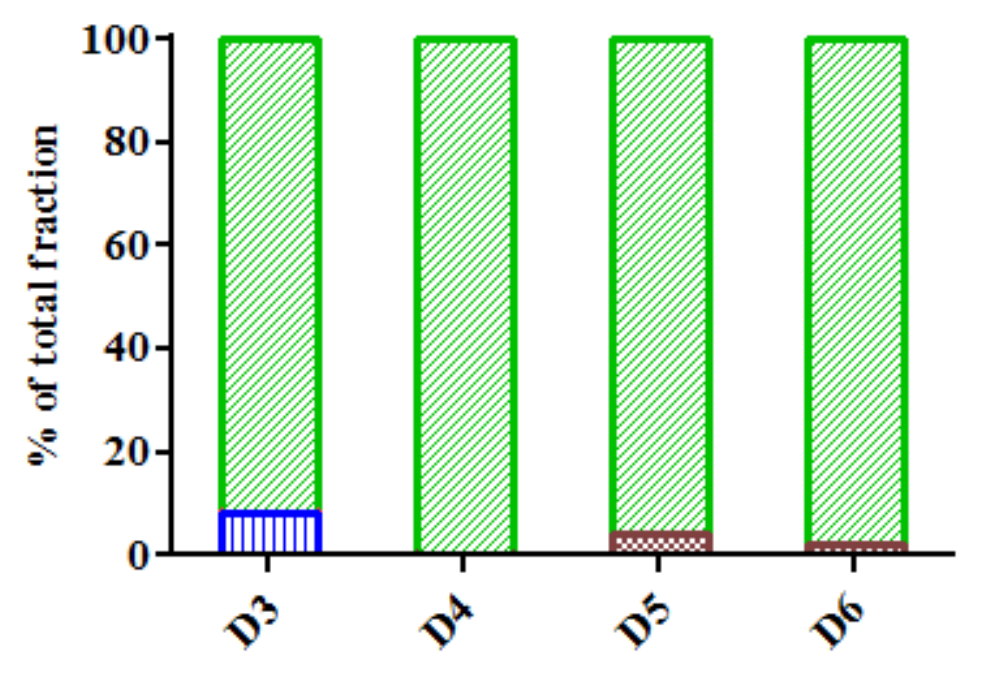

1x Sorption

(n) Hydrolysis

$\square$ Outflow

Volatilization

b) $55^{\circ} \mathrm{C}$

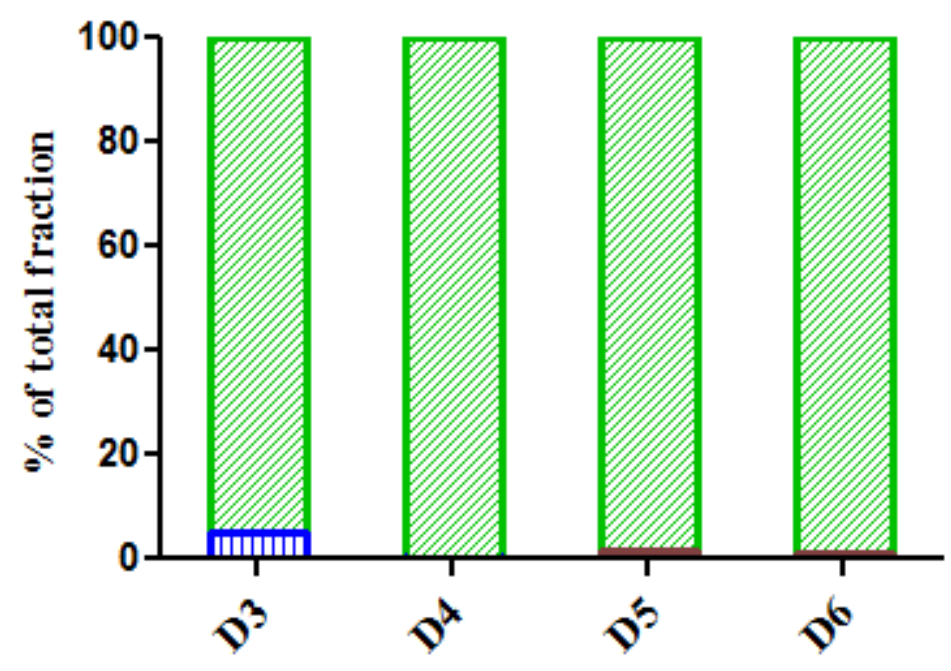

× Sorption

(n) Hydrolysis

E Outflow

Volatilization

Fig. 2. Fate of target siloxanes during one-stage (a) mesophilic and (b) thermophilic anaerobic sludge digestion. 
a)
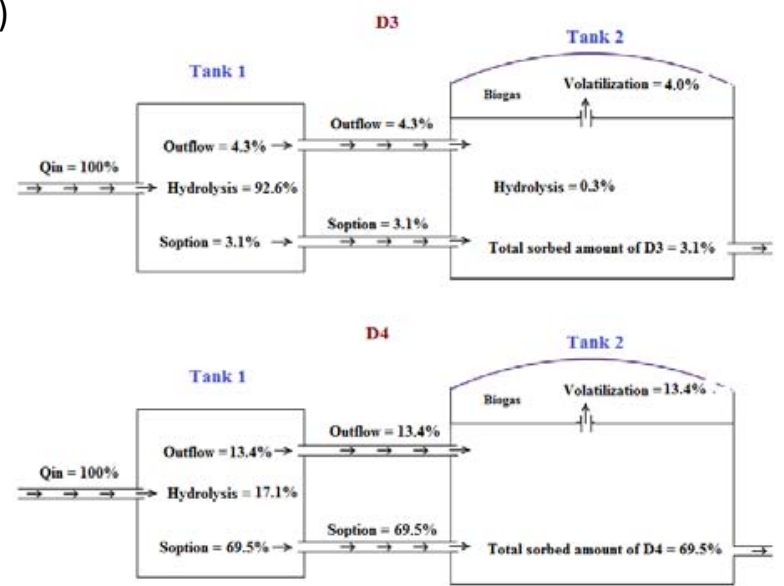

b)
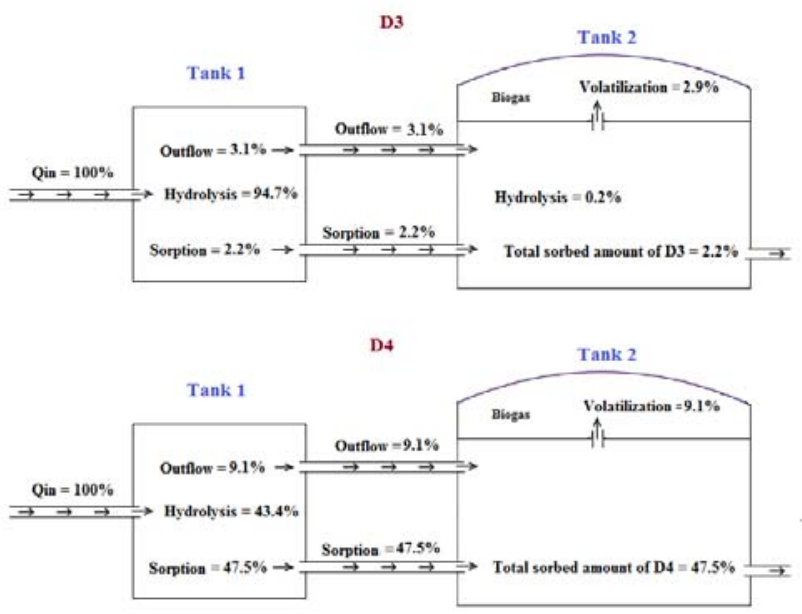

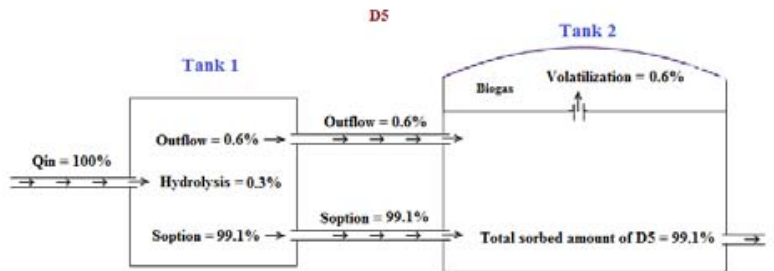

D6

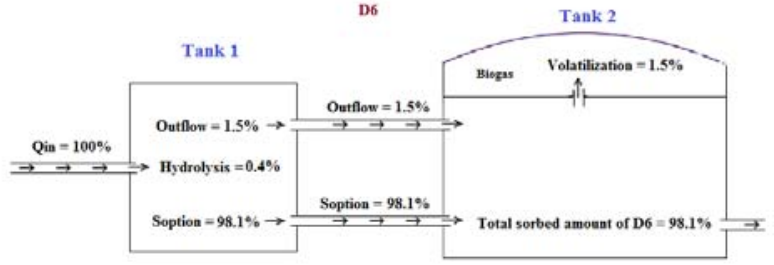

D5

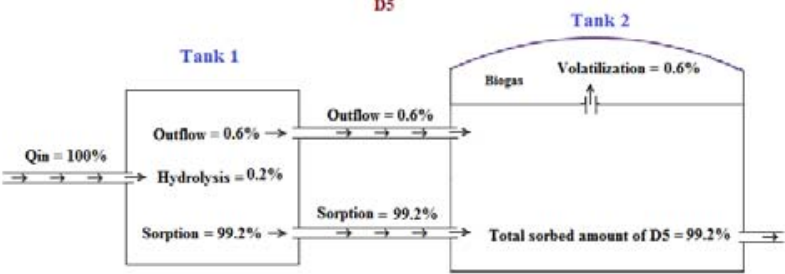

D6

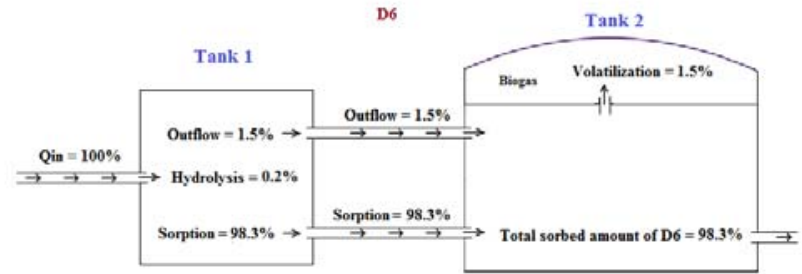

Fig. 3. Fate of D3, D4, D5 and D6 during (a) mesophilic and (b) thermophilic two-stage anaerobic sludge digestion (Tank 1: pre-digester; Tank 2: anaerobic digester). 